\title{
Analysis of Didactical Trajectories in Teaching and Learning Mathematics: Overcoming Extreme Objectivist and Constructivist Positions
}

\author{
Juan D. Godino ${ }^{1}$, Hernán Rivas ${ }^{2}$, María Burgos ${ }^{1}$, Miguel R. Wilhelmi ${ }^{3 *}$ \\ ${ }^{1}$ University of Granada, SPAIN \\ ${ }^{2}$ Pontificia Universidad Católica de Chile, CHILE \\ ${ }^{3}$ Public University of Navarra, SPAIN \\ *CORRESPONDENCE: $₫$ miguelr.wilhelmi@unavarra.es
}

\begin{abstract}
There is currently a consensus in mathematics education that favors constructivist instructional models, which are based on the inquiry of knowledge by students. There are, however, different views that consider objectivist models, based on knowledge transmission (direct or explicit teaching) more effective in the teaching of scientific disciplines. In this article we analyze an instructional process on elementary probability directed to prospective primary education teachers, which was designed under constructivist principles and is based on data analysis projects. A systematic analysis of the study process reveals that the optimization of the learning process involves implementing frequent moments that require explicit transmission of knowledge by the teacher. This analysis is based on some theoretical tools from the onto-semiotic approach to mathematical knowledge and instruction, which allow identifying significant didactical facts that support a mixed instructional model. The relevance for mathematics education to contemplate the use of mixed instructional models that articulate constructivists and objectivist approaches to promote mathematical learning is concluded.
\end{abstract}

Keywords: mathematics instruction, didactical models, onto-semiotic approach, probabilistic notions, teacher training

\section{INTRODUCTION}

Learning in general, and in particular mathematics learning depends on many factors. The selection of situations - problems which contextualize and give meaning to curricular contents, the way to interact and the resources used are determining factors in the students' learning. This complexity explains that there are different instructional theories supported by different epistemological, psychological and pedagogical assumptions.

A variety of models and theories of instructional design have been developed in the field of Mathematics Education and for specific areas. The theories in question are understood as a corpus that "offers an explicit guide about the best way to help people learn and develop" (Reigeluth 2000, p. 15). They are directed towards practice and describe educative methods and situations in which the aforementioned methods should be used.

Godino, Batanero, Cañadas and Contreras (2015) make a synthesis of instructional models in mathematics education in which the inquiry and construction of the knowledge by the students themselves, and of others who play an important role in the transmission of knowledge, are privileged. Likewise, they discuss the need

Article History: Received 8 August $2018 \bullet$ Revised 1 October $2018 \bullet$ Accepted 1 October 2018

(C) 2019 by the authors; licensee Modestum Ltd., UK. Open Access terms of the Creative Commons Attribution 4.0 International License (http://creativecommons.org/licenses/by/4.0/) apply. The license permits unrestricted use, distribution, and reproduction in any medium, on the condition that users give exact credit to the original author(s) and the source, provide a link to the Creative Commons license, and indicate if they made any changes. 
to implement a mixed instructional model, which draws up the construction/inquiry with the transmission of knowledge in order to achieve a mathematics instruction that locally optimizes the resources available and maximizes the potential learning in one specific context. These authors support a mixed model of mathematics instruction basing their views on a cognitive and onto-semiotic kind of reasons (following the conclusions of Sweller, Kirschner, \& Clark 2007), by assuming the assumptions of the Onto-semiotic Approach of mathematical knowledge and instruction (OSA) (Font, Godino, \& Gallardo 2013; Godino, Batanero, \& Font 2007).

In this article we argue that a mixed instructional model favours the acquisition of mathematical knowledge and the teacher's management of the student's emerging knowledge. To support this hypothesis, we carry out the description and analysis of a teaching experience of probabilistic notions with prospective primary school teachers. We suggest that general theories of human learning should be adapted according to the types of knowledge to be learnt. "We believe that the critical question instructional designers must ask is not "Which is the best theory?" but "Which theory is the most effective in fostering mastery of specific tasks by specific learners?" (Ertmer \& Newby, 1993, p. 61). In particular, which paradigm is most effective, objectivist or constructivist?

\begin{abstract}
"The objectivist paradigm is based on the assumption that there is a real world and the purpose of education is to map the entities of that world on the learner's mind. The constructivist paradigm is based on the idea that reality is constructed during interaction with the environment and peers and that knowledge is both individual and communal [...] Radicals of each camp argue that is impossible to mix the two paradigms [...] However, dominant paradigms, in both the physical and social sciences, [...] they tend to co-exist and are used whenever they are appropriate". (Vrasidas, 2000, 358-359)
\end{abstract}

To follow, we firstly present a summary of previous research from different authors who have defended one of these extreme instructional positions. Then some theoretical notions of OSA which are the foundation of our analysis are described, and, to follow, the design of an instructional process in which elementary probabilistic notions directed to teachers at the beginning of their training, is studied; this process was carried out following constructivist principles of teaching and was based on data analysis projects. Next the didactic trajectory implemented is analysed, identifying significant didactic facts, which show potential factors that could condition the learning achieved. In the following sections, the synthesis of the didactic trajectory implemented with one group of students is presented. Finally we discuss the implications that the results have in order to analyse the existing tension between the moments of investigation and transmission in the study of mathematics, and the convenience of adopting a mixed model of instruction to increase the didactical suitability of the process.

\title{
BACKGROUND
}

The debate between the types of schools that "transmits knowledge" and the types of schools that "builds knowledge" seems at present to lean towards the second. "The constructivist learning framework is a foundation for today's K-12 mathematics reform. Many future teachers across the United States are being taught that this is the way students learn best" (Andrew, 2007, p. 157). This preference can be observed in the curricular orientations of different countries, which are supported by the adoption of constructivist or socioconstructivist theoretical frameworks.

\begin{abstract}
"Students learn more and learn better when they can take control of their learning by defining their goals and monitoring their progress. When challenged with appropriately chosen tasks, students become confident in their ability to tackle difficult problems, eager to figure things out on their own, flexible when exploring mathematical ideas and trying alternative solution paths, and willing to persevere" (NCTM, 2000, p. 20).
\end{abstract}

The family of instructional theories called "Inquiry-Based Education" (IBE), "Inquiry-Based Learning" (IBL), "Problem-Based Learning" (PBL), postulate the learning based on the investigation with very little guide from the teacher (Artigue \& Blomhøj, 2013).

The different varieties of constructivism share among others, the supposition that learning is an active process, that knowledge is built rather than innate or passively absorbed and that to achieve an effective learning it is necessary to pose students with significant, open and challenging problems (Ernest, 1994; Fox, 2001). 
Table 1. Characteristics of objectivism and constructivism as the basis of instruction

\begin{tabular}{|c|c|c|}
\hline Dimensions & Obje & Cons \\
\hline $\begin{array}{l}\text { (Nature of } \\
\text { knowledge } \\
\text { object of } \\
\text { instruction) }\end{array}$ & $\begin{array}{l}\text { - Knowledge has an existence external to the subject. } \\
\text { - Knowledge structure is determined by concepts, } \\
\text { properties and relationships. } \\
\text { - Meaning corresponds to world entities and } \\
\text { categories, independent of the understanding of any } \\
\text { subject. } \\
\text { - Symbols represent reality. }\end{array}$ & $\begin{array}{l}\text { edge depends on the subject's mental activity. } \\
\text { ucture of knowledge depends on experience } \\
\text { rsonal interpretations. } \\
\text { ag is not based on a correspondence with the } \\
\text { it depends on personal understanding. } \\
\text { ls are tools to construct reality. }\end{array}$ \\
\hline $\begin{array}{l}\text { (Learning of } \\
\text { knowledge, } \\
\text { skills and } \\
\text { dispositions) }\end{array}$ & $\begin{array}{l}\text { - The mind is a symbol processor and reflects reality. } \\
\text { - Thinking is based on structured, recognizable and } \\
\text { transmissible accumulation of factual knowledge. } \\
\text { - Prior students' knowledge and the answers they } \\
\text { provide during the learning process are accepted if } \\
\text { they agree with the objective knowledge. } \\
\text { - Student's reflection is irrelevant and unnecessary. }\end{array}$ & $\begin{array}{l}\text { - The mind is a builder of symbols and a conceptual } \\
\text { system that builds a reality. } \\
\text { - Thinking is based on the perception and grows from } \\
\text { physics, physical and social experience. } \\
\text { - Prior students' knowledge and the answers they } \\
\text { provide condition instruction, which must be adapted } \\
\text { to the students' conceptual frameworks. } \\
\text { - Students' reflection and exploration are the engine of } \\
\text { problem solving and inquiry into the situations posed. }\end{array}$ \\
\hline $\begin{array}{l}\text { (Means and } \\
\text { interaction } \\
\text { pattern) }\end{array}$ & $\begin{array}{l}\text { - The teacher is the source of the knowledge that is } \\
\text { object of teaching. } \\
\text { - Student exploration is unnecessary and, therefore, } \\
\text { is not stimulated. } \\
\text { - Interactions between students are unnecessary, } \\
\text { because learning is an individual act. } \\
\text { - Reproduction of objective knowledge culturally } \\
\text { accepted is emphasized. } \\
\text { - Errors are used as an opportunity to reinforce the } \\
\text { right behaviour. }\end{array}$ & $\begin{array}{l}\text { - The teacher acts as a coach, leading the emerging } \\
\text { knowledge in cooperative contexts. } \\
\text { - Student exploration is essential and, therefore, is } \\
\text { stimulated. } \\
\text { - Interactions between students inside and outside the } \\
\text { classroom are promoted, because learning is a social } \\
\text { act. } \\
\text { - Solving tasks in contextualized environments } \\
\text { emphasizes the construction of knowledge. } \\
\text { - Students take responsibility for their own learning. }\end{array}$ \\
\hline
\end{tabular}

However we also find authors that defend an opposite point of view to the previous one, as is the case of Mayer (2004), Kirschner, Sweller and Clark (2006) and Sweller, Kirschner and Clark (2007). These authors send us to a wide range of research works that conclude about the greater effectivity of the instructional models where the teacher, and the transmission of knowledge are given a relevant role.

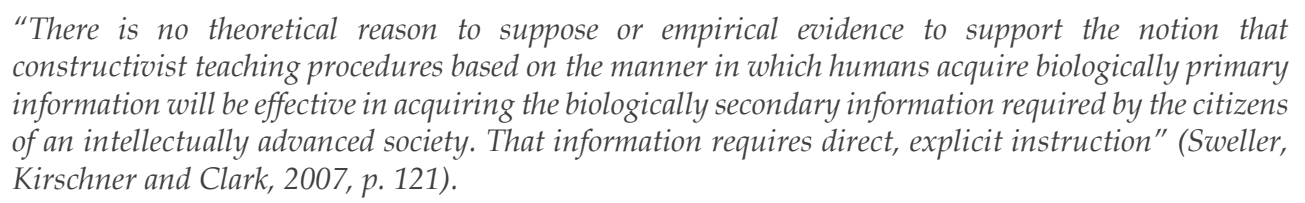

The aforementioned authors affirm that the empirical research of the last half a century about this problem, provide overwhelming and clear evidence that a minimum guide during the instruction is significantly less effective and efficient than a guide specifically designed to support the cognitive process necessary for the learning. Similar results are reflected in the meta-analysis carried out by Alfieri, Brooks, Aldrich and Tenenbaun (2011). In a similar vein Radford affirms, "Indeed, it does not seem reasonable to expect that the child (working alone or in collaborative groups) would be capable of reconstructing by him/herself the complex theories featured in the curriculum" (Radford, 2012, p.103).

The problem posed about the inquiry and transmissive instructional models can be related to the debate between constructivism and objectivism (Jonassen, 1991), as well as to teaching models focused on the student or on the teacher respectively (Stephan, 2014). Whitin objectivism, in particular in its conductist version, knowledge is publicly observable and the learning consists of the acquisition of this knowledge by means of the interaction between stimula and responses. Frequently, the form of conditioning used to achieve desirable verbal conducts is by means of direct instruction or lecture - based pedagogy (Boghossian, 2006).

In Table 1 we present the main features of the objectivist and constructivist perspectives considered in this paper as extreme ideal alternatives when applied in instructional design. They are grouped into three dimensions: epistemic (knowledge which is the object of instruction), cognitive (learning of knowledge, skills and dispositions), and instructional (means and modes of interaction). These features have been summarized from the works of various authors (Andrew, 2007; Boghossian, 2006; Ernest, 1994; Jonassen, 1991; Murphy, \& McCornick, 1997). 
Objectivism and Constructivism are two extremes that are hardly proposed as isolated methods in teaching instruction. Researches try to overcome the dualistic tension between these two extremes of constructivism and objectivism, in advocating a mixed type of instruction. For example, Ku, Ho, Hau and Lai (2014) along a process of teaching critical thinking, made an instructional intervention with quantitative methodology and compared three instructional modes: a) direct instruction, b) inquiry-based teaching, and c) a mixed instruction that combines aspects of these previous two methods. Their conclusions highlight the benefits of adopting more than one instructional approach to teach critical thinking. "The inquiry-based and the direct instruction should not be made exclusive in the classrooms. Future research should direct towards how best to bridge the two approaches in order to maximize their benefits on students' learning" (p. 263). The quoted authors also believe that teachers should not underestimate the benefits of direct instruction to stimulate the quality of students' thinking. Lobato, Clarke and Ellis (2005) also analyse how the direct introduction of new information and ideas can be articulated with the constructivist tenets.

\section{THEORETICAL FRAMEWORK}

Our analysis is based on the Onto-semiotic Approach (OSA) to mathematical knowledge and instruction (Godino, Batanero, \& Font 2007), where theoretical tools that enable us to describe and understand the dynamics of the processes of mathematics instruction have been developed and can support a theory of mixed instructional design aforementioned. We will use the notions of didactic configuration, didactic trajectory, didactic suitability (Godino, Contreras, \& Font 2006; Godino 2013), and significant didactic fact (SDF) (Godino, Rivas, Arteaga, Lasa \& Wilhelmi 2014), which are summed up to follow, in this paper.

\section{Didactic Configuration}

A didactic configuration is any segment of didactic activity (teaching and learning) carried out between the beginning and the end of a task (situation - problem). So, this includes the students' and the teachers' actions, as well as the resources planned or used to carry out the task. The sequence of didactic configurations makes up a didactic trajectory. The didactic trajectory includes as one of its components, what other authors describe as "hypothetical learning trajectory" (Simon 1995; Simon \& Tzur 2004) since not only do we take into account the objectives, instructional tasks and hypothesis about the learning process, but also the roles of the teachers and learners and the instructional resources used.

The task, which defines a didactic configuration, can be formed by different subtasks each one of which can be considered as a sub-configuration. In any didactic configuration there is: a) an epistemic configuration (system of institutional mathematical practices, objects and processes, required in the task), b) an instructional configuration (system of teacher/learner functions and instructional means which are used in addition to the interaction between the different components) and c) a cognitive-affective configuration (system of personal mathematical practices, objects and processes that describe the learning and the affective components which accompany it).

Figure 1 summarizes the components and internal dynamic of the didactic configuration, the relations between teaching and learning and the main mathematics processes lined to the onto-semiotic modelisation of mathematics knowledge (Font, Godino \& Gallardo, 2013; Godino, Font, Wilhelmi \& Lurduy, 2011). This modelisation takes into account the complexity of the relations that are established in the centre of any didactic configuration, not reducible to moments of inquiry or transmission of knowledge.

In Figure 1, with the bottom arrow, from learning to teaching, we want to point out that the relations are not linear but cyclical. In one particular moment of investigation, for example, the learner interacts with the epistemic configuration without the intervention of the teacher (or with less influence). This interaction conditions the teachers' interventions and so, should be taken into account in the instructional configuration, perhaps not totally in its content, but yes however in its nature, need and use. This is obviously not prerogative of the inquiry moments. The cognitive trajectory produces examples, meanings, arguments, etc., which condition the study process and as a result, the epistemic and instructional configurations, thus making possible and committing - in all cases, conditioning- , the conclusion of the instructional project planned. 




Figure 1. Components and internal dynamic of a didactic configuration (Godino et al., 2015, p. 2646)

\section{Significant Didactic Facts}

The detailed analysis of a process of mathematics study, which permits to reveal the dialectic and synergy between the different components of the didactic system, requires to be divided into units where the notion of configuration and subconfiguration is useful. In turn, the attention can be focused on certain significant didactical facts defined by Godino et al. (2014):

\section{"A didactic fact is significant if the actions or didactical practices that make it up carry out a function, or admit an interpretation, in terms of the instructional objective intended. The significantness can be understood from the point of view of the teacher, of the student, or else from an institutional point of view which is external to the didactic system, that is from the subject that has carried out the preliminary study and the instructional design." (Godino et al., 2014, p. 7).}

So these SDF are contextual, that is to say, one same mathematical fact can be significant in one context and not in another. Furthermore, a SDF can be significant in one context because it generates suitable conditions to acquire knowledge or, to the contrary, to prevent the access planned. Thus additional tools, which permit the foundation of the SDF to be identified and interpreted, are necessary. The notion of didactic suitability (Godino, Batanero \& Font, 2007; Godino, 2013), theirs facets and components help to give meaning to didactical facts.

\section{Didactic Suitability}

The didactic suitability (Godino et al., 2007; Godino, 2013) of a process of instruction is defined as the degree at which the said process (or part of the same) meets certain characteristics that enable us to say it is optimum or adequate to be adapted among the personal meanings achieved by the students (learning) and the institutional meanings intended or implemented (teaching), taking into account the circumstances and the resources available (context). This supposes the coherent articulation of six facets or dimensions: epistemic, ecological, cognitive, affective, interactional and mediational (Breda, Font and Pino-Fan, 2018). 
Statement of the Project "Throwing two dice"

We are going to play with two dice in couples. We throw the dice and add the points obtained. If the result is $6,7,8$, or 9 , player A wins a counter; if the result is different then player B wins a counter.

a) Do you prefer to be player A or B? Reason you answer.

b) Is this game fair? Does one player have an advantage over another according to the rules of the game? Who has more probability of winning? Reason the answers.

c) Simulate the throwing of the dice. Play with one team-mate 10 times and write down the result of the totals that you obtain. Who has won more times, A or B? Do you think the result will be repeated if we play 100 times more? Why? Reason your answers.

Once the data has been collected for the set of couples formed in the class, the following questions are considered:

a) Who has won more times, players A or B? What has happened? Why didn't A win more as was expected? What can a teacher do in this situation to explain the results to his/her students?

b) Construct a bar diagram where the bars are side by side and which represents the relative frequency distribution and the probability distribution of the random variable "sum of points after throwing two dice". How will this diagram change if instead of representing the relative frequencies by throwing 100 times, they had thrown 10000 times?

Figure 2. Project "Throwing two dice"

The notion of didactic suitability and its six facets provides criteria to delimit the significantness of the didactic facts that occur in the processes of mathematics studies. A didactical fact is considered to be significant if it provides relevant empirical information on the process development regarding to the suitability criteria previously established in any of the facets. In this paper we are interested in identifying the features of the process that correspond to the constructivist or objectivist teaching models, and in highlighting the synergy that can be established between them. We support the hypothesis that the proper coordination between the inquiry and transmission moments is a key factor to achieving high didactical suitability in the instructional process.

\section{METHOD}

\section{Context and Participating Sample}

The training process about the content of descriptive statistics and probability was carried out in the context of a subject in the Degree for Primary Teachers, where "mathematics bases for primary education" are tackled. One group of 58 students were assigned to one of the authors of the paper. This subject includes a topic about "Introduction to statistics and probability" which supposes three weeks of class, of around 3 hours of work per week in sessions of complete groups and one weekly session of 1.5 hours of practical work with the group divided into three subgroups. The study is organised on the basis of the development of the data analysis projects, a teaching approach, which is new for the majority of students and supposes a methodology that future teachers can transfer to their professional work in Primary Education.

We briefly describe one of the projects directed towards contextualising the study of probabilistic notions and whose implementation provides significant didactic facts that we will use as support in the theoretical reflection about the dialect between the moments of inquiry and transmission in the processes of mathematics instruction.

\section{"Throwing two dice" Project}

In the "Throwing two dice Project", several questions which enable us to contextualise the study of elementary probabilistic notions, are considered: random experiment, sample space, Laplace's rule and the law of big numbers. The questions proposed to the students are presented in Figure 2. The study process linked to the "Throwing two dice" Project was implemented in two class sessions (corresponding to three chronologic hours).

The study process implemented contemplated, as well as carrying out the Project "Throwing two dice", the following instructional resources:

- Study text; Stochastic for teachers (Batanero \& Godino 2003), where the basic statistics and probability contents are developed.

- A collection of solved exercises given to the student for personal study, aided by tutorial sessions. 
- Virtual teaching notice board, which is used as a repository of information and as an asynchronous communication space between the students and the teacher.

The use of these resources supposes that the students are committed with the study process, not only in face-to-face sessions in which there is dialogue, where they work cooperatively with class-mates and receive information and feedback from the teacher but also outside the classroom they personally study the complementary resources made available to them.

The teaching methodology designed follows, therefore, the principles of constructivist approaches. However, some empirical data recorded by non-participant observation, show that the effective development of the data analysis project includes frequent transmission moments that were not foreseen in the teacher's design. These transmission moments were induced by emerging conflicts of learning. As a result a mixed instructional model was applied, in which moments of direct teaching, predominantly knowledge transfer, take place within the framework of an overall constructivist design. The analysis of the instructional process effectively implemented included in the next section reveals the dialectical tension between transmission and inquiry that helped increase the didactic suitability of the process.

\section{RESULTS}

\section{Significant Didactic Facts in the Didactic Trajectory Implemented}

The didactic activity carried out between the teacher and the students to give an answer to each question and the resources used make up a didactic configuration, and the sequence of these configurations is the didactic trajectory implemented.

To follow, some SDF, which have taken place in the implementation of the Project "Throwing two dice", are presented in order to clarify this notion and its interest in the analysis of the instruction process. Later, a synthesis of the didactic trajectory implemented is included; taking into account the totality of the SDF that had taken place in the study process. The synthesis is carried out by classifying the SDF according to the epistemic-ecological, cognitive-affective and instructional (interactional and mediational) dimensions.

SDF 1: (Trasmission of knowledge by the teacher)

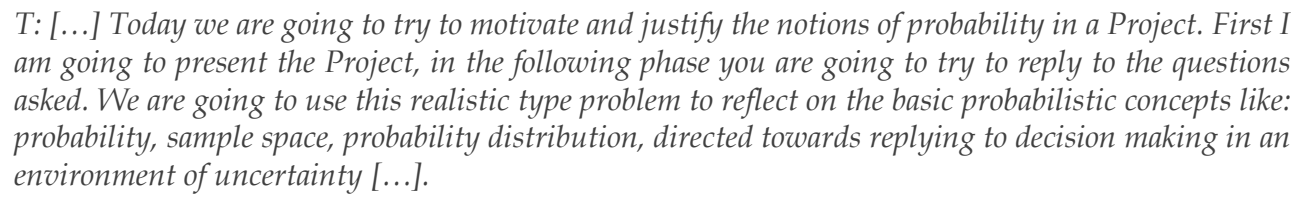

This episode is considered a significant didactic fact because it describes a phase of the process in which the teacher transmits information to the students about the way in which they are going to proceed in the study of probabilistic notions. This didactical fact is clearly transmissive, but it is immersed in a didactic situation with essential constructivist features. The teacher indicates that he is going to propose a set of questions related to the Project. This Project is a realistic type situation-problem, which requires the use of probabilistic concepts; so this corresponds to the epistemic facet. The students should try to answer the questions asked; and to do so they should assume a certain degree of responsibility when investigating and answering the questions, which would imply the interactional facet. In this episode the affective facet is also present when the teacher tries to relate the probabilistic concepts implied in the Project with its role in the decision-making in the environment of uncertainty.

SDF 2: (Dialogic-inquiry interaction)

T: [...] What have you put?

S5: It is better to be B, because he has more probability of winning.

T: Why?

S5: Because A has 4 numbers and B has up to 12

T: Look carefully at the problem and try to explain was has been done [...]. 


\begin{tabular}{|c|c|c|c|c|c|}
\hline & & & 4 & 5 & 6 \\
\hline & & & 5 & 6 & 7 \\
\hline & & & 6 & 7 & 8 \\
\hline & & & 7 & 8 & 9 \\
\hline & & & 8 & 9 & 10 \\
\hline & & & 9 & 10 & 11 \\
\hline & & & 10 & 11 & 12 \\
\hline
\end{tabular}

SAMPLE SPACE:

\begin{tabular}{c|c} 
Value & Probability \\
\hline 2 & 0,028 \\
\hline 3 & 0,056 \\
\hline 4 & 0,083 \\
\hline 5 & 0,111 \\
\hline 6 & 0,139 \\
\hline 7 & 0,167 \\
\hline 8 & 0,139 \\
\hline 9 & 0,111 \\
\hline 10 & 0,083 \\
\hline 11 & 0,056 \\
\hline 12 & 0,028 \\
\hline
\end{tabular}

$\{2,3,4,5,6,7,8.9,10,11,12\}$

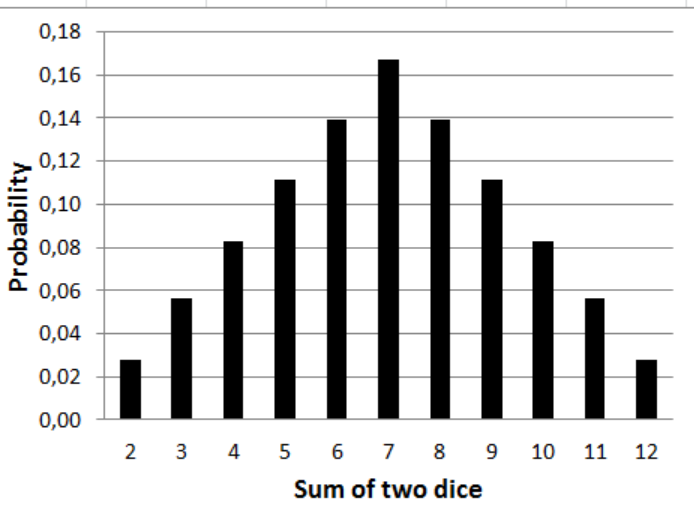

Figure 3. Institutionalisation of the knowledge intended

The students try to respond to the first question, "Do you prefer to be player A or B? Reason your answer", working in pairs or small groups; the teacher progressively asks for the answers. We consider this short episode to be an SDF because one student answers wrongly because he does not understand the sample space of the experiment (this implies the cognitive facet). He justifies the answer taking into account the number of results in which each player wins, and not the possible totals for each result; this supposes an abusive application of Laplace's probability, without observing the need for the cases to be equiprobable.

From the interactional point of view, we observe a conversational format of interaction between the teacher and the students, in addition to a constructivist organization of the teaching-learning process on the part of the teacher who expects the students to determine the correct answer without needing him to do so.

SDF 3: (Institutionalisation of the knowledge intended)

T: [...] We are going to systematise this content. We have here the total points after throwing the dice. [A table with the possible cases of the experiment is presented, Figure 3]. We have the two dice, dice one and dice two: if we throw the dice and we add the points there are 36 possible cases of sums. The sums are the following 2, 3, 4, 5, 6, 7, 3, 4,... The sample space of the random experiment of throwing the dice and adding them is 2, 3, 4, 5, 6, 7, 8, 9, 10, 11, 12. These are the 11 different possibilities of sums $[\ldots]$.

[...] In this experiment we have to see from the 36 possible cases, in how many cases A wins and how many cases $B$ wins? There are 20 cases in which $A$ wins and 16 where $B$ wins. There are more cases where A wins [...].

\section{$T:[\ldots]$ Let's see the second question "Is this game fair?"}

S16: No, player A has more possibility to win.

T: What is the probability that A wins?

S16: 20 divided by 36.

T: This calculation has been done by applying Laplace's rule...

In this episode the teacher proceeds to institutionalise the knowledge used to answer the first two questions. Neither the solution obtained by each student nor the degree of understanding with respect to these questions, is known, although it can be deduced from previous episodes that the level of knowledge is uneven: some prefer to be player A and others B, based on the results of their experiments and in some cases based on probabilistic arguments. The teacher's explanation (transmission of knowledge) is necessary to advance in the study process, since to intend that all the students (or the great majority) discover the institutional solution intended in a reasonable time seems an illusion. After the presentation and explanation of the table where the possible results of the experiment and the possible sums are represented, the questions about whether the game is fair and the probability that A will win obtain immediate response from the students. 
SDF 4: (Dialogic institutionalisation of the law of big numbers)

T: [...] Let's see what has happened with the simulation we have done? Who has won more times A or $B ?$

S17: We found that A won.

S18: Our result is that $A$ wins.

S19: We got the same result. A wins.

S20: A wins.

S21: According to our results B wins.

T: Let's go the next question "Do you think that the result will be repeated if we play 100 times more? Why?"

S22: It wouldn't happen again because we are talking about probability and there isn't a rule, which enables us to determine the results.

T: Fine, however, one of the things that have happened in the experiment is that A has almost always won. You say that we don't know exactly what is going to happen with 100 throws, because it is a random experiment and B could win. Fine. Let's imagine now that we play 100 times more, a lot more, what will happen?

S22: Player A will win.

T: That means that in the long run $A$ is expected to win although in some experiment the opposite could happen.

S23: What happens is that 100 times are few; it is necessary to do the experiment many times.

T: So, an important question is the size of the sample for the predictions to be fulfilled [...].

In this episode the teacher and the students share knowledge about the random behaviour of the experiment; they are not sure whether A or B will win even although the experiment is repeated 100 times but, "in the long run A is expected to win, although in some experiments the opposite could happen". The teacher is introducing (transmitting) an approximation of the law of big numbers by following the intuition of at least one of the students who affirms that "Player A will win".

The study process continues to be the mixed type inquiry-dialogic-transmissive "didactic model" which has appeared in the SDF previously described. The notion of random variable, probability distribution and frequency distribution are introduced and illustrated by comparing the corresponding bar diagrams.

\section{Synthesis of the Didactic Trajectory Implemented}

In addition to the examples shown in the previous section, other SDF, which we synthesize to follow, were identified and classified depending on how they involved the epistemic and ecological, cognitive and instructional (interactional and mediational) facets. The affective facet was not object of specific observation, although we can affirm that, in general, the students were interested and committed with the development of the project during the class sessions.

\section{SDF relative to the epistemic and ecological dimensions}

Where it is indicated whether the instructional model of each fact is eminently constructivist (CONST), transmissive (TRANS), or MIXED.

- (TRANS) During session 2 the teacher shows some computer programmes that enable to graphically justify the convergence of the frequencies relative to probability. He simulates the dice throwing and the coin tossing in front of the whole class. 
- (MIXED) Translation processes are proposed between different representations: sums obtained when throwing two dice on counting tables, possible cases in probability distribution tables and of sums obtained in frequency tables, representation of the probability and frequency distribution in graphs.

- (TRANS) The teacher goes over the basic probability concepts and definitions (random experiment, possible cases, sample space, favourable cases, Laplace's rule, probability distribution, proportion, statistics variable, percentage, frequency distribution, attached bar graphs, tree diagram) in specific interventions and during the presentation of the expected solution to the whole class.

- (TRANS) The main properties of the topic (Laplace's rule, the empirical law of big numbers, the convergence of the frequencies relative to probability) are given by the teacher through specific institutionalizations and content synthesis presented in the class.

- (CONST) The students have the opportunity to graphically compare the probability distribution of the "Throwing the two dice" experiment with the frequency distribution since they have done the experiment 100 times. To do this they manually draw graphs and also use the calculation sheet.

- (MIXED) During the development of the project, the teacher permanently favours the ability to argue, asking the students to justify their answers in a reasoned way.

- (TRANS) In different moments the teacher establishes connections with the school curricula and "real" situation of the social and cultural surroundings (ecological facet).

\section{SDF relative to the cognitive dimension}

Faced with the question "do you prefer to be player A or B?", we observe different conflicts which oblige the teacher to intervene to try to solve them, and therefore they are TRANS moments referring to individual students or to the whole class:

- Think that all the results of the experiment are equiprobable (bias of equiprobability).

- Difficulty to determine the possible sums and obtain the sample space of the experiment.

- The students do not manage to represent the possible sums when they throw the two dice (use of the two way table and the tree diagram).

- Conflicts when making the attached bar diagram.

- There are students who use the absolute frequencies instead of relative frequencies when comparing the two distributions (probability and frequency distribution).

- All the bars are built together like a histogram.

- Neither title nor labels are included in the graph.

The regulative nature of the representation conventions, statistical concepts and procedures themselves, as well as the difficulties that arise in the study process require frequent teacher's explanations and direct instructions. The students' prior knowledge, the heterogeneity of the group and the time constraints are determining factors that hinder the implementation of a pure constructivist teaching model.

\section{SDF relative to the interactional and mediational dimension}

- (MIXED) In the work activities in small groups, the teacher permanently supports the students' work but clearing up doubts and assessing what they have learnt (spontaneous assessment). Faced with some difficulties, there are times when he insinuates the solution by reducing the initial difficulty of the project.

- (TRANS) In the processes of institutionalisation, the teacher conveniently systematizes the main content of the topic.

- (CONST) The physical simulation of the dice using pieces of paper has been quite efficient, even although at the beginning some difficulties arose.

The SDF analysis identified in the epistemic and ecological facets represents a discrete description of the epistemic trajectory implemented, that is the concepts, representations, propositions, procedures and probabilistic justifications that have been dealt with in class to reply to the questions asked. Those corresponding to the interactional and mediational facets enable us to recognise the role of the teacher and the students in the management of this knowledge where a certain predominance of the transmission of 
knowledge with respect to students' self research is shown. Likewise, it is important to point out that both models do not have temporary stagnant moments, strictly delimited. It is normal to find the determination of sequences where the study process is managed with dialogic moments where the students' answers are good as origin and motivation to a teacher's explanation.

The sequence of SDF relative to the cognitive facet shows the students' progressive building of knowledge, the conflictive points that are presented and whether these conflicts are recognised and cleared up by the teacher. The comparison using attached bar diagrams of the relative frequency and probability distributions has also required specific attention.

\section{DISCUSSION: THE TENSION BETWEEN INQUIRY AND TRANSMISSION}

In the implementation of the study process we have identified frequent teacher's interventions that reduce the cognitive task demand, by proposing the students an easier problem or by providing information that the students should know or look for themselves. These interventions represent SDF: they constitute an example of funnel interaction pattern (Bauersfeld, 1988; Voigt, 1985). Moreover the format of cooperative work by means of the organization of students' teams who tackle the problem solving, on certain occasions makes the outstanding students answer the questions and blockages of the less capable ones who frequently limit themselves to doing what their classmates do.

By using the notion of suitability we can say that in this way the learning objectives are reduced and so the epistemic suitability of the intended mathematics activity decreases. Furthermore the interactional suitability also decreases suppressing or reducing the student's autonomy. However, the cognitive suitability increases; this is understood here as practising specific routines, when faced with an absence of knowledge acquisition of a considerable part of the students in a merely transmissive instruction. In fact, the affective suitability increases thus avoiding frustration and student withdrawal.

The explanations and changes in the tasks are given within a group, by the teacher when he is questioned by a group, or by one member on an individual level. The moments of institutionalisation, understood as moments of regulation, that is, segments of didactic activity in which socio-mathematical norms are reminded or set (Yackel, \& Cobb, 1996) and epistemic rules which come from institutionalized mathematics practice (Font, Godino \& Gallardo, 2013), are dense in the process of mathematics instruction. The institutionalization can take place in the phases of collective presentation of the tasks, so that the students can understand and come to terms with them (the teacher goes over linguistic conventions, concepts, procedures or properties supposed known). It can also happen in the exploratory phase of the work (individually or team work) where the teacher goes over, clears up or introduces norms to a student or a small group who is blocked and cannot progress in the required mathematical activity. These specific moments of institutionalization, although they frequently reduce the learning expectations, try to improve the cognitive, affective and temporary suitability of the instruction process.

The analysis of observations has revealed frequent transmissive moments, not envisaged by the teacher, which could even be considered as behaviourists:

- The process has been orientated towards the learning of scientific knowledge that has an external cultural existence (concepts, procedures, probabilistic representations).

- The teacher has finally been the source of the said cultural knowledge whose institutionalisation he has assumed.

- The solution to the task is not negotiable. The concepts and properties, which have to be applied to find the solution to the problem, although they can admit different more or less formal formulations, are epistemic rules, which should be respected.

- The previous knowledge of the students and the answers they give during the process are accepted if they agree with those of the teacher.

On the other hand, we have shown that in the development of the instruction process there have been moments, which agree with assumptions of constructivist pedagogy:

- The activity has been orientated towards problem solving.

- The teacher has acted as a coach.

- The students' ideas and strategies have been shown. 
- The mistakes and understanding of the students has been used to provide feedback.

- The students have been encouraged to explore the situation posed so that they themselves can find the solution.

- A collaborative and cooperative learning has been favoured.

Hudson, Miller and Butler (2006) justify the implementation of mixed instructional models that adapt and mix the explicit instruction (focused on the teacher) with the instruction based on problem solving (focused on the learner) by the need to carry out curricular adaptations due to the differences in student abilities. Similar conclusions were reached by Steele (2005), for whom "The best teaching will integrate often thoughts from constructivist and behaviourist principles" (p. 3).

\section{FINAL OBSERVATIONS}

The analysis carried out of the didactic trajectory provides reasons in favour of designing and implementing a mixed type instructional model which includes moments of inquiry, cooperative, or dialogic work, and also moments based on knowledge transmission; these reasons refer to the nature of mathematics objects. The students have to learn rules, in addition to the circumstances for a correct application. "Truth is dictated by science and mathematics' respective regimes of truth, which serve to structure what is to be expected from the subject" (Radford, 2012, p. 108).

The learner starts from known rules (concepts, propositions and procedures) and produces others that should be shared and compatible with those already established in mathematics culture. These rules (knowledge) have to be stored in the long term memory of the student and used in the correct moment of the short term memory.

The theoretical tools applied in this work have enabled us to reveal that the development of a mathematics class, although initially focused on the solving of a situation-problem (project) has to contemplate moments of transmission of knowledge on the part of the teacher. This means sharing with the students an example which has been totally developed, but with a mixed dynamic where the students have to get involved, based on memory and the application of probabilistic notions and techniques they have learnt in secondary school, in the acquisition of a mathematics meaning that can be used in their future professional life.

The analysis of the session has shown that the moments of students' inquiry to answer the questions asked are linked to clearly transmissive moments of the teacher, which involve the whole class, groups of students or individuals. The teacher's interventions in these moments of knowledge transmission frequently cannot be foreseen in the design phase. The teacher establishes rules of the study process linked more than to moments or phases of the proposed situation, to the students' behaviour observed, which are indicators of semiotic conflicts, or of progress in the acquisition of meanings.

It has been shown that in the implementation phase of the instructional process, the notions of configuration, subconfiguration, significant didactic fact and didactic suitability enable us on one hand to delimit and condense the chronic of the study process and on the other hand, give a description and make a detailed analysis of the contents involved, the patterns of interaction and the conflicts that have taken place. The analysis carried out support the affirmation that the optimization of learning implies a dialectic and complex combination between the roles of the teacher as instructor (transmissor) and facilitator (coach) and the roles of the student as knowledge builder and active receiver of significant information. The need for this mixed model is reinforced by the need to adapt the educative project to the temporary restriction and the diversity of ways and rhythms of learning in large groups of students. "Given the myriad of potential design situations, the designer's "best" approach may not ever be identical to any previous approach, but will truly "depend upon the context" (Ertmer \& Newby, 1993, p. 62).

Mathematics teaching and in particular statistics, should start from, and focus on, the use of situationsproblems (data analysis projects), as a strategy to give meaning to the theory and techniques studied, and to favour exploratory moments of mathematics activity. However, in mathematics practise, configuration of mathematics objects intervene (concepts, proposition, procedures, arguments) (Font, Godino, \& Gallardo 2013), which should be recognised by the teacher in order to plan the study. These objects should be progressively dominated by the students if we want to progress towards successive advanced levels of knowledge and competence. 
The relevance of mixed models, which combine objectivist and constructive perspectives, should guide the use of Information and Communication Technologies (ICT) in teaching and learning processes. ICT in many cases place the emphasis on autonomous learning, in which the student will resort to moments of transmissive learning. For example, flipped classroom (Reidsema, Kavanagh, Hadgraft, \& Smith, 2017) is an instructional strategy and a type of blended learning that integrates two strategies, face-to-face and virtual; this second strategy is, in many cases, rather transmissive (for instance, in a flipped classroom, students watch online lectures). Thus, the generalized use of ICT in teaching and learning processes suggest a future line of research for analysing the significance of objectivist and constructive perspectives.

Moreover, in future works, we consider also measuring the competences and skills of the teachers who participate in the project, keep in mind three dimensions (Pino-Fan, Assis \& Castro, 2015): 1) mathematical dimension (about "the knowledge that allows the teacher to solve the problem or mathematical activity that is to be implemented in the classroom and link it with mathematical objects that can later be found in the school mathematics curriculum", p. 1433); 2) didactical dimension (which considers six facets: epistemic, cognitive, affective, interactional, mediational and ecological); and 3) meta didactic-mathematical dimension (about the norms and meta-norms in teaching and learning processes).

\section{ACKNOWLEDGEMENTS}

Work carried out in the framework of the research project EDU2016-74848-P (FEDER, AEI).

\section{Disclosure statement}

No potential conflict of interest was reported by the authors.

\section{Notes on contributors}

Juan D. Godino - University of Granada, Spain.

Hernán Rivas - Pontificia Universidad Católica de Chile, Chile.

María Burgos - University of Granada, Spain.

Miguel R. Wilhelmi - Public University of Navarra, Spain.

\section{REFERENCES}

Alfieri L., Brooks P. J., Aldrich N. J., \& Tenenbaum H. R. (2011). Does discovery-based instruction enhance learning? Journal of Educational Psychology, 103(1), 1-18. https://oi.org/10.1037/a0021017

Andrew L. (2007). Comparison of teacher educators' instructional methods with the constructivist ideal. The Teacher Educator, 42(3), 157-184. https://doi.org/10.1080/08878730709555401

Artigue M., \& Blomhøj M. (2013). Conceptualizing inquiry-based education in mathematics. ZDM Mathematics Education, 45, 797-810. https://doi.org/10.1007/s11858-013-0506-6

Batanero C., \& Godino J. D. (2003). Estocástica y su didáctica para maestros [Stochastics and its didactics for teachers]. Departament of Mathematics Education, University of Granada: Granada. Retrieved from http://www.ugr.es/local/jgodino

Bauersfeld H. (1988). Interaction, construction, and knowledge: Alternative perspectives for mathematics education. En T. Coony \& D. Grows (Eds.), Effective Mathematics Teaching (p. 27-46). Reston, VA: NCTM/Erlbaum.

Boghossian P. (2006). Behaviorism, constructivism, and Socratic pedagogy. Educational Philosophy and Theory, 38(6), 713-722. https://doi.org/10.1111/j.1469-5812.2006.00226.x

Breda A., Font V., \& Pino-Fan L. (2018) Criterios Valorativos y Normativos en Didáctica de las Matemáticas: el Caso del Constructo Idoneidad Didáctica. Bolema, 32(60), 255-278. https://oi.org/10.1590/19804415v32n60a13

Ertmer P. A., \& Newby T. J. (1993). Behaviorism, cognitivism, constructivism: comparing critical features from an instructional design perspective. Performance Improvement Quarterly, 6(4), 50-72. https://oi.org/10.1111/j.1937-8327.1993.tb00605.x 
Font V., Godino J. D., \& Gallardo J. (2013). The emergence of objects from mathematical practices. Educational Studies in Mathematics, 82, 97-124. https://doi.org/10.1007/s10649-012-9411-0

Fox R. (2001). Constructivism examined. Oxford Review of Education, 27(1), 23-35. https://doi.org/10.1080/03054980125310

Godino J. D. (2013). Indicadores de la idoneidad didáctica de procesos de enseñanza y aprendizaje de las matemáticas [Didactic suitability indicators of mathematics teaching and learning processes]. Cuadernos de Investigación y Formación en Educación Matemática, 11, 111-132.

Godino J. D., Batanero C., \& Font, V. (2007). The onto-semiotic approach to research in mathematics education. ZDM. The International Journal on Mathematics Education, 39(1-2), 127-135. https://doi.org/10.1007/s11858-006-0004-1

Godino J. D., Batanero C., Cañadas G. R., \& Contreras, J. M. (2015). Linking inquiry and transmission in teaching and learning mathematics. In K. Krainer \& N. Vondrobá (Eds.), Proceedings of the Ninth Conference of the European Society for Research in Mathematics Education (CEME9, 4-8 February 2015) (pp. 2642-2648). Prague, Czech Republic: Charles University in Prague, Faculty of Education and ERME.

Godino J. D., Contreras A., \& Font, V. (2006). Análisis de procesos de instrucción basado en el enfoque ontológico-semiótico de la cognición matemática [Analysis of instructional processes base on the ontosemiotic approach of mathematics cognition]. Recherches en Didactiques des Mathematiques, 26(1), 3988.

Godino J. D., Font V., Wilhelmi M. R., \& Lurduy O. (2011). Why is the learning of elementary arithmetic concepts difficult? Semiotic tools for understanding the nature of mathematical objects. Educational Studies in Mathematics, 77(2-3), 247-265. https://doi.org/10.1007/s10649-010-9278-x

Godino J. D., Rivas H., Arteaga P., Lasa A., \& Wilhelmi M. R. (2014). Ingeniería didáctica basada en el enfoque ontológico - semiótico del conocimiento y la instrucción matemáticos [Didactic engineering based on the onto-semiotic approach to mathematical knowledge and instruction]. Recherches en Didactique des Mathématiques, 34(2/3), 167-200.

Hudson P., Miller S. P., \& Butler F. (2006). Adapting and merging explicit instruction within reform based mathematics classrooms. American Secondary Education, 35(1), 19-32.

Jonassen D. H. (1991). Objectivism vs. constructivism: do we need a new philosophical paradigm? Educacional Technology Research \& Development, 39(3), 5-14. https://doi.org/10.1007/BF02296434

Kirschner P. A., Sweller J., \& Clark R. E. (2006). Why minimal guidance during instruction does not work: An analysis of the failure of constructivist, discovery, problem-based, experiential, and inquiry-based teaching. Educational Psychologist, 41(2), 75-86. https://doi.org/10.1207/s15326985ep4102_1

Ku K.Y. I., Ho I. T., Hau K. T., \& Lai, E. C. M. (2014). Integrating direct and inquiry-based instruction in the teaching of critical thinking: an intervention study. Instructional Science, 42, 251-269. https://doi.org/10.1007/s11251-013-9279-0

Lobato J., Clarke D., \& Ellis A. B. (2005). Initiating and eliciting in the aching: a reformulation of telling. Journal for Research in Mathematics Education, 36(2), 101-136.

Mayer R. E. (2004). Should there be a three-strikes rule against pure discovery learning? American Psychologist, 59(1), 14-19. https://doi.org/10.1037/0003-066X.59.1.14

National Council of Teachers of Mathematics (NCTM) (2000). Principles and standards for school mathematics. Reston, VA: National Council of Teachers of Mathematics.

Pino-Fan L., Assis A., \& Castro W. F. (2015). Towards a methodology for the characterization of teachers' didactic-mathematical knowledge. Eurasia Journal of Mathematics, Science \& Technology Education, 11(6), 1429-1456.

Radford L. (2012). Education and the illusions of emancipation. Educational Studies in Mathematics, 80, 101118. https://doi.org/10.1007/s10649-011-9380-8

Reigeluth C. M. (2000). ¿En qué consiste una teoría de diseño educativo y cómo se está transformando? En C. M. Reigeluth (Ed.), Diseño de la instrucción. Teorías y modelos. Un nuevo paradigma de la teoría de la instrucción (pp. 15-40). Madrid: Santillana.

Simon M. A. (1995). Reconstructing mathematics pedagogy form a constructivist perspective. Journal for Research in Mathematics Education, 26, 114-145. https://doi.org/10.2307/749205 
Simon M. A., \& Tzur R. (2004). Explicating the role of mathematical tasks in conceptual learning: An elaboration of the Hypothetical Learning Trajectory. Mathematical Thinking and Learning, 6(2), 91104. https://doi.org/10.1207/s15327833mt10602_2

Steele M. M. (2005). Teaching students with learning disabilities: Constructivism of behaviorism? Current Issues in Education, 8(10). Retrieved from http://cie.ed.asu.edu/coume8/number10

Stephan M. (2014). Learner-Centered teaching in mathematics education. In S. Lerman (Ed.), Encyclopedia of Mathematics Education. Berlin: Springer. https://doi.org/10.1007/978-94-007-4978-8_87

Sweller J., Kirschner P. A., \& Clark R. E. (2007). Why minimally guided teaching techniques do not work: A reply to commentaries. Educational Psychologist, $42(2), \quad$ 115-121. https://doi.org/10.1080/00461520701263426

Voigt J. (1985). Patterns and routines in classroom interaction. Recherches en Didactique des Mathématiques, $6(1), 69-118$.

Vrasidas, C. (2000). Constructivism versus objectivism: Implications for interaction, course design, and evaluation in distance education. International Journal of Educational Telecommunications, 6(4), 339362.

Yackel E., \& Cobb P. (1996). Sociomathematical norms, argumentation, and autonomy in mathematics. Journal for Research in Mathematics Education, 27(4), 458-477. https://doi.org/10.2307/749877 